How do you feel about math?

“How do you feel about Math?": Relationships between Competence and Value Appraisals, Achievement Emotions and Academic Achievement

Francisco Peixoto, Lourdes Mata, Vera Monteiro and Cristina Sanches CIE - ISPA; ISPA - Instituto Universitário

The published manuscript is available at http://link.springer.com/article/10.1007/s10212-016-0299-4

doi: 10.1007/s10212-016-0299-4

This research was supported by the FCT - Science and Technology Foundation under Grant PTDC/CPE-CED/121358/2010.

Correspondence concerning this article should be addressed to Francisco Peixoto, Department of Educational Psychology, ISPA - Instituto Universitário, Rua Jardim do Tabaco, n³4, 1149-041 Lisbon, Portugal.

e-mail: fpeixoto@ispa.pt 
How do you feel about math?

\title{
“How do you feel about Math?”: Relationships between Competence and Value Appraisals, Achievement Emotions and Academic Achievement
}

\begin{abstract}
This study analyzes the relationships between cognitive appraisals, classroom and test emotions and math achievement in a sample of 1219 Portuguese students from the $6^{\text {th }}$ and $8^{\text {th }}$ grades. Participants completed measures of Perceived Value, Perceived Competence and seven Math achievement emotions (boredom, hopelessness, anger, anxiety, enjoyment, pride and relief) experienced in two different settings: Classroom and Tests. Math achievement was obtained from school records.

Results showed significant associations between students competence and value appraisals, their emotional experiences in test and classroom situations, and their math achievement. However, when emotions were considered simultaneously in Structural Equation Modelling, only anger in test situations and hopelessness were significant negative predictors of students math achievement. Hopelessness appears to play a particular role in the interplay between cognitive appraisals, emotions and academic achievement as it is the only emotion that relates to math achievement both in test and classroom situations. Furthermore, findings also support the existence of differences in the relationships between cognitive appraisals and the achievement emotions students experience in these two settings.
\end{abstract}

Keywords: Achievement Emotions, Cognitive appraisals, Competence perception, Value, Math Achievement 
How do you feel about math?

\section{Introduction}

Educational settings are places where different types of emotions (e.g. social and achievement) are experienced (e.g. Meyer and Turner 2006; Pekrun et al. 2007; Weiner 2007). The study of achievement emotions in educational settings has burgeoned in the last decade as researchers have found that other emotions besides anxiety play an important role in the learning processes (e.g. Pinxten et al. 2014; Lichtenfeld et al. 2012; Meyer and Turner 2006; Pekrun 2006; Pekrun et al. 2007). Despite these findings, research on math achievement emotions still remains strongly focused on the adverse effects of math anxiety on student achievement and performance. Relying on the core predictions of Control-Value Theory of Achievement emotions (CVT, Pekrun 2006, 2009), the current research focuses on the interplay between some antecedents of emotions (e.g. value and perceived competence), seven different achievement emotions, as well as the effects of these emotions on the math performance of early adolescents.

The Control-Value Theory of Achievement Emotions

One of the most comprehensive theoretical frameworks explaining the role played by emotions in the learning processes is Control-Value Theory (Pekrun 2006, 2009), which looks at emotions as a multidimensional construct, composed of affective, cognitive, motivational, expressive, and physiological processes. Within the CVT achievement emotions are defined as emotions that are directly related to achievement activities or to achievement outcomes evaluated by standards of excellence (Pekrun 2006, 2009). Achievement emotions can be conceptualized in two ways: as state-achievement emotions, that is transitory emotional states which occur within specific situations and over brief periods of time (e.g. the anxiety experienced immediately before starting an exam), or as trait-achievement emotions which refer to the typical emotional states repeatedly experienced in specific situations but for longer periods of time, therefore making them more stable (e.g. the general feeling of anxiety towards mathematics-related activities). 
How do you feel about math?

The CVT classifies achievement emotions according to a three-dimensional taxonomy (Pekrun 2006; Pekrun et al. 2007): object focus (on the ongoing activities vs. on the resulting outcomes, these then being subdivided into prospective vs. retrospective emotions); valence (positive vs. negative, or pleasant vs. unpleasant); and degree of activation (activating vs. deactivating).

According to CVT (Pekrun 2006), the kind of achievement emotions experienced at school is determined by environmental, situational and individual factors and may produce quite different effects on student learning and achievement. This theory asserts that control and value appraisals are the proximal determinants of achievement emotions establishing the idea that "being in control of, or out of control of, achievement activities and outcomes that are subjectively important” leads individuals to experience different emotions (Pekrun 2009, p.99). Control appraisals concerning activities and outcomes are determined by causal expectations of success or failure and by causal attributions. Among the determinants of causal expectations we can take into consideration people's beliefs about their own competence (e.g., self-efficacy, self-concept, competence self-perception) which determine their expectations of success or failure. Value appraisals include both the intrinsic and the extrinsic value ascribed to achievement activities and outcomes. Higher levels of perceived control are assumed to elicit positive emotional experiences such as hope, enjoyment, or pride, while lower levels of perceived control are expected to produce the opposite effect, eliciting negative emotional experiences such as hopelessness, anger or anxiety (Pekrun 2006).

Empirical evidence has shown that positive achievement emotions are positively associated with student control and value appraisals (Burić and Sorić 2012; Pekrun et al. 2004; Pekrun et al. 2011), self-efficacy perceptions (Artino et al. 2010; Feldman and Kubota 2015), competence beliefs (Winberg et al. 2014), competence expectations (Pekrun et al 2006), grade expectations (Levi et al. 2014), and academic self-concepts (Frenzel et al. 2007; Goetz et al 2010; Pekrun et al. 2006), while the opposite pattern has generally been found for negative achievement emotions (Artino et al. 2010; Burić and Sorić 2012; Dettmers et al. 2011; Frenzel 
How do you feel about math?

et al. 2007; Goetz et al. 2010; Kyttälä and Björn2010; Pekrun et al. 2006; Pekrun et al. 2011; Sorić et al. 2013).

Besides these proximal antecedents (control and value appraisals) CVT also takes into consideration more distal antecedents that affect the control and value appraisals, namely achievement goals or control and value beliefs. School and social environments can also influence individual control-value appraisals through interactions, feedback, quality of instruction, expectancies of significant others, etc., as they communicate information related to controllability and academic values affecting the individual's achievement emotions (Pekrun 2006; Pekrun et al. 2007). Emotions are also influenced by non-cognitive factors including genetic dispositions and temperament (Pekrun et al. 2007).

According to CVT, the overall effects of emotions on academic achievement are assumed to depend on the interplay between task demands and a set of motivational and cognitive mechanisms triggered by different emotions. Among those mechanisms are the cognitive resources available, the kind of learning and self-regulation strategies adopted, student effort and motivation (Pekrun 2006; Pekrun et al. 2007), which are directly related to achievement and performance (for a meta-analytic review see Richardson et al. 2012). Following the assumptions of CVT (e.g. Pekrun 2006; Pekrun et al. 2002; Pekrun et al. 2009), research with undergraduate students has shown that positive activating emotions such as enjoyment, pride and hope, positively affect learning and performance (Artino et al. 2010; Pekrun et al. 2004; Pekrun et al. 2009; Pekrun et al. 2011), by strengthening interest, motivation and effort, promoting self-regulation of learning, the use of more flexible and creative learning strategies and making cognitive resources available, which allows students to direct their attention towards the task (Pekrun et al. 2004; Pekrun et al. 2011).

Conversely, and in line with the CVT predictions (Pekrun 2006; Pekrun et al. 2002), empirical evidence has shown that negative deactivating emotions, such as boredom, sadness, or hopelessness, diminish interest and motivation, trigger the use of more rigid and superficial learning strategies and lead to external regulation of learning (Pekrun et al. 2004; Pekrun et al. 2010; Pekrun et al. 2011). Moreover, they reduce the cognitive resources available for task 
How do you feel about math?

performance, by directing students' attention away from the task and causing irrelevant thinking during learning and taking tests (Daniels et al. 2009; Malkovsky et al. 2012; Pekrun et al. 2004; Pekrun et al. 2011). Consequently, data from correlational and longitudinal studies has shown that these negative deactivating emotions have a negative impact on the academic achievement of both high-school students (Au et al. 2010; Burić and Sorić 2012) and university students (Artino et al. 2010; Daniels et al. 2009; Lam et al. 2015; Pekrun et al. 2009; Pekrun et al. 2010; Pekrun et al. 2011; Pekrun et al. 2014).

In CVT (Pekrun 2006; Pekrun et al. 2002) the effects of positive deactivating and negative activating achievement emotions are more complex and ambivalent. While positive deactivating emotions, such as relief, relaxation, or contentment, may not foster student attention focus, or their motivation in the short-term, they may reinforce student motivation to invest effort in the long term. Therefore, positive deactivating emotions may have a detrimental effect on immediate performance but a beneficial effect in the long term (Pekrun et al. 2002). Research on the effects of positive deactivating emotions is almost nonexistent, but it suggests that their effect on academic performance is positive (Lam et al. 2015; Pekrun et al. 2011). Relief, for example, was found to be positively related to the use of elaboration strategies, selfregulation, and extrinsic motivation, but unrelated to self-efficacy, effort, or intrinsic motivation (Pekrun et al. 2011).

Negative activating emotions, such as anger, frustration, anxiety or shame, are generally considered to be detrimental to student learning and performance since they reduce intrinsic motivation and foster task-irrelevant thinking by directing attention towards the object of emotions (Pekrun 2006). However, anger, frustration or shame may also produce the opposite effect by strengthening student extrinsic motivation and getting them to try harder and invest more in order to avoid future failure, therefore having a positive effect on future performance (Pekrun et al. 2002). Anxiety, which is traditionally assumed to be negatively related to achievement and performance, may also, within certain limits, be beneficial for performance by spurring students to action. 
How do you feel about math?

Empirical evidence on the effects of negative activating emotions comes majorly from research on anxiety. Overall it indicates that these emotions are positively related to external regulation (Pekrun et al. 2011), attention problems and irrelevant thinking in classes or when taking tests (Daniels et al. 2009; Pekrun et al. 2004), and negatively related to student interest, motivation, effort, self-regulation and use of elaboration strategies (Artino et al. 2010; Pekrun et al. 2004; Pekrun et al. 2011), as well as to achievement and performance (Artino et al. 2010; Ahmed et al. 2010; Daniels et al. 2009; Goetz et al. 2012; Pekrun et al. 2004; Pekrun et al. 2004, 2009, 2011; Villavicencio and Bernardo, 2013). However, these relationships are sometimes negative and are sometimes not significant (e.g. Pekrun et al. 2004).

Although CVT posits that environmental factors, achievement goals and cognitive appraisals will elicit certain emotions which will, in turn, affect learning and performance, it also acknowledges that student experiences of success and failure regarding their achievement and performance will feed back on student emotions, their control and value-appraisals, their achievement goals and expectations, and on the social environment (Pekrun 2006; Pekrun et al. 2002). Therefore, the relations between antecedents, emotions and their effects are complex and dynamic processes that are more likely explained by reciprocal causation over time than by a simple linear unidirectional causation (Pekrun 2006, 2013; Pekrun et al. 2007), as recent empirical evidence is starting to confirm (Pekrun, et al. 2010; Pekrun et al. 2014; Pinxten et al. 2014).

Math achievement emotions and student performance

Pekrun and collaborators (e.g. Goetz et al. 2008; Goetz et al. 2007; Pekrun 2006) state that, like other control- and value-related constructs (e.g. self-concepts of ability, achievement expectancies), achievement emotions should be conceived as domain-specific (e.g. towards mathematics, sciences, languages, etc.) instead of generalized personality traits.

Mathematics is one of the most important school subjects. However, it is also considered to be one of the most difficult and therefore is amongst the most feared by students (Dündar et al. 2014). Longitudinal research on math results in some countries has shown that 
How do you feel about math?

proficiency in mathematics is a strong predictor of positive outcomes for young adults (OECD 2014). This data is particularly important as it has also been reported that foundation skills in mathematics can have a major impact on individual life chances because "poor mathematics skills severely limit people's access to better-paying and more-rewarding jobs" (OECD 2014, p.252). Promoting the development of math skills is therefore critical, implying not only accounting for the best ways to teach math competences and skills but also in understanding student cognitive and emotional experiences in regard to mathematics.

Research on achievement emotions related to math has shown that positive activating emotions (e.g. math enjoyment and pride) are positively related to student attention in the classroom (e.g. Luo et al. 2014), to their use of self-regulated learning strategies (e.g. Ahmed et al. 2013) and to math achievement (Ahmed et al. 2010; Ahmed et al. 2013; Goetz et al. 2008; Goetz et al. 2007; Villavicencio and Bernardo 2013). However, some studies have found contradictory results, such as a non-significant relationship (Luo et al. 2014) or even a negative relationship (Pinxten et al. 2014) between math enjoyment and achievement after controlling for math competence beliefs, which according to Pinxten et al. (2014) may be due to the strong correlations between enjoyment and competence beliefs.

Empirical research addressing the influence of negative activating or deactivating achievement emotions on student math performance is scarce, with the exception of studies on anxiety, but it generally indicates that these emotions are detrimental to student math performance. Although Luo et al. (2014) have not found a significant effect of math boredom, other studies consistently indicate that this emotion negatively predicts student math achievement (Ahmed et al. 2013; Dettmers et al. 2011).The same negative influence was found for hopelessness (Burić and Sorić 2012) and for anger reported by students during mathematics homework (Dettmerset al. 2011).

Research on math anxiety is extensive and it strongly indicates that math anxiety has a negative influence on student math achievement and performance (e.g. Ahmed et al. 2010; Dettmers et al. 2011; Luo et al. 2014; Radišić et al. 2015; Wu et al. 2014). Math anxiety was also found to be positively related to classroom disruption (Luo et al. 2014; Radišić et al. 2015) 
How do you feel about math?

and to attention problems which in turn were negatively related to math performance (Wu et al. 2014). Despite the strong empirical evidence on the adverse effects of math anxiety, some research has either found a positive relationship between math anxiety and performance (e.g. Ma and Xu 2004; Macher et al. 2013) or has not found a significant relationship using both correlational (Meece et al. 1990) and longitudinal data (Kyttälä and Björn 2010). These results are however in line with the CVT argument that the effects of negative activating emotions are ambivalent, being in some cases positive but in others negative. According to Keeley et al. (2008) these apparently contradictory results may be explained by means of a curvilinear relationship between mathematics anxiety and student performance, where anxiety may be beneficial to student achievement and performance up to a certain limit after which it starts to be detrimental.

\section{Current research}

Following the theoretical framework of the CVT (Pekrun 2006, 2013), the present study examined the relationships between the cognitive appraisals, the emotional experiences and the performance of pre-adolescents and early adolescents. Although there is some empirical evidence on the nature of these relationships, it mostly arises from studies using samples of undergraduate (e.g. Artino et al. 2010; Feldman and Kubota 2015; Pekrun et al. 2004, 2006, 2011) and high school students (e.g. Burić and Sorić 2012; Dettmers et al. 2011; Goetz et al. 2010; Kyttälä and Björn 2010; Sorić et al. 2013). Studies with younger students are rare (e.g. Erturan and Jansen 2015; Frenzel et al. 2007) and studies with pre-adolescents and early adolescents are lacking (Huang 2011).

Since research has shown that achievement emotions, as well as their cognitive antecedents, are organized in domain-specific ways (e.g. Goetz et al. 2006, 2007, 2008), the current paper specifically addresses the effects of cognitive appraisals and achievement emotions in relation to math on pre and early adolescent math performance. The pattern of relationships was examined using seven discrete achievement emotions instead of using only one emotion as it does in a number of studies (e.g. Erturan and Jansen 2015; Kyttälä and Björn 
How do you feel about math?

2010; Goetz et al. 2013; Pekrun et al. 2014; Wu et al. 2014) or a composite of positive vs. negative emotions (e.g. Dettmers et al. 2011; Lam et al. 2015; Lipnevich et al. 2012; Mega et al. 2014; Sorić et al. 2013). Thus in this study we tested the following hypotheses (Figure 1):

Hypothesis 1: Students cognitive appraisals (perceived math competence and perceived math value) are positive predictors of pleasant achievement emotions (enjoyment, pride and relief) and negative predictors of unpleasant achievement emotions (hopelessness, boredom, anger and anxiety). The strength of these associations is however expected to be greater for positive activating and negative deactivating emotions.

Hypothesis 2: Pleasant emotions are positive predictors of student performance in mathematics, while unpleasant emotions are negative predictors of math performance. Once again, the strength of these relationships is expected to be greater in the case of positive activating and negative deactivating achievement emotions.

--- Figure 1 about here ---

To ensure that the associations are not explained by other related variables, gender and previous math achievement were controlled. Although gender differences in math achievement and performance are frequently nonexistent (e.g. Lindberg et al. 2010), research has shown that girls tend to report lower math competence beliefs than boys (Else-Quest et al. 2010; Goetz et al. 2013; Kyttälä and Björn 2010). With regard to prior achievement, research has shown that it is one of the strongest predictors of subsequent achievement (e.g. Pekrun et al. 2010; Pekrun et al. 2014). The models also take into account that perceived competence and value can have a direct positive effect on math achievement (Pinxten et al. 2014).

Some authors have also reinforced the need to examine these emotional experiences and other school-related variables taking into account the specific setting in which they occur, namely in classes, tests or homework (e.g. Dettmers et al. 2011; Trautwein et al. 2006). Previous findings indicate that pre-adolescents differentiate emotions in different situations (Peixoto et al. 2015), although research hardly ever compares students emotional reactions in different contexts (exceptions Goetz et al. 2012; Lipnevich et al. 2012; Racanello et al. 2013). Research has generally taken into account only one context (e.g. Artino et al. 2010; Dettmers et 
How do you feel about math?

al. 2011; Pekrun et al. 2009; Pekrun et al. 2014), or emotions globally, regardless of the context in which they occur (e.g. Frenzel et al. 2007; Lichtenfeld et al. 2012). As such, research comparing the structural relationships between control appraisals and emotions in different situations is lacking. Goetz et al. (2012) compared the relationships between self-concept and emotions across different situations (classroom and homework) and found that these relationships were stronger for classroom emotions. Pekrun et al. (2011), despite not addressing this issue, presented results showing differences in the strength of the correlations between emotions and task value and self-efficacy. For some emotions those differences were higher between classroom and test emotions than between learning/homework and classroom emotions. Additionally, research showed differences in emotions level between test and class or homework situations (Raccanello et al. 2013). Therefore, we also examine early adolescents emotional experiences in regard to mathematics in two different settings: classes and tests, testing the following hypothesis:

Hypothesis 3: The relationships between cognitive appraisals and emotions in class situations are stronger than in test situations.

\section{Method}

Participants

The participants comprised 1219 students, aged 11 to $16(M=12.53 ; S D=1.36), 51.5 \%$ of whom were girls. Those students attended the $6^{\text {th }}\left(\mathrm{N}=647,51.7 \%\right.$ girls, $M_{\text {age }}=10.5, S D_{\text {age }}=$ $.74)$ and the $8^{\text {th }}$ grade $\left(\mathrm{N}=572,51.3 \%\right.$ girls, $\left.M_{\text {age }}=12.7, S D_{\text {age }}=.88\right)$ in 12 public schools in Lisbon, and $18.1 \%$ had already repeated a school year. The Portuguese educational system is organized in 3 cycles: the $1^{\text {st }}$ takes place over four years ( $1^{\text {st }}$ to $4^{\text {th }}$ grade, corresponding to elementary school), the $2^{\text {nd }}$ over two years $\left(5^{\text {th }}\right.$ and $6^{\text {th }}$ grade, called preparatory school) and the $3^{\text {rd }}$ over three years $\left(7^{\text {th }}\right.$ to $9^{\text {th }}$ grades, corresponding to middle school). Following this students enter high school, which is a further three ( $10^{\text {th }}$ to $12^{\text {th }}$ grades $)$. The $2^{\text {nd }}$ and $3^{\text {rd }}$ cycles are organized in a similar way differing only in the number of school subjects $\left(8\right.$ in the $2^{\text {nd }}$ cycle and 
How do you feel about math?

10 in the $3^{\text {rd }}$ cycle), and they share the same physical space, separate from elementary school and usually also from high school.

Measures

Perceived competence and perceived value measures were both taken from the Portuguese version of the Intrinsic Motivation Inventory (IMI) (Monteiro et al. 2015).Three items were used to measure math perceived competence (e.g. "I think I am quite good at Math's activities") and another three to measure math intrinsic perceived value (e.g. "Math's activities are valuable to me").Answers to these two measures were given on a 6-point scale $(1=$ Never to $6=$ Always).Cronbach's Alpha for perceived competencewas 0.85 and 0.89 for perceived value. Achievement emotions were measured using the Achievement Emotions Questionnaire for Pre-adolescent students (AEQ-PA, Peixoto et al. 2015), which comprises two scales, each one with 24 items, assessing six emotions in two situations: classroom and tests. The classroom version assesses: boredom (e.g. "I get bored during math classes"), hopelessness (e.g. "It's pointless to prepare for my math class since I don't understand the material anyway"), anger (e.g. "I feel anger welling up in me during my math class"), anxiety (e.g. "I feel nervous in my math classes"), enjoyment (e.g. "I enjoy being in my math class"), and pride (e.g. "I am proud of the contributions I have made in my math class"). The test version assesses the same emotions but with relief (e.g. "After a math test, I feel very relieved") instead of boredom. Both versions include achievement emotions experienced before, during and after classes / tests, thus giving a more complete view of student emotional experiences at different times. Answers were given on a 5-point Likert scale $(1=$ completely disagree to $5=$ completely agree $)$ and scores were calculated by averaging all the items pertaining to each achievement emotion. Scores for classroom and test emotions were calculated separately, as recommended by Peixoto et al. (2015). Cronbach's Alpha ranged from .79 for anxiety to .93 for boredom in the classroom version, and from .84 for enjoyment to .88 for anxiety and pride in the test version. 
How do you feel about math?

Math achievement was obtained from school records and consisted on the average of the grades obtained by students in Mathematics at the end of the three school terms, which range from 1 (lowest grade) to 5 (highest grade).

Control Variables. Students' gender (coded 1 for males and 2 for females) and their prior math achievement were included as covariates in the analyses. Prior math achievement consisted of students' final math grade $\left(3^{\text {rd }}\right.$ term) in the previous school year.

Procedure

After obtaining consent from the school boards, written parental consent was obtained for all participants in the study. Students took part on a voluntary basis and were assured of the confidentiality of their answers. Data was collected in different sessions along with other measures as this study was included in a broader research project. For half of the participants the classroom-related emotions were collected jointly with perceived competence and perceived value in the same session and the test-related emotions were collected in another session. For the second half, test-related emotions were collected jointly with perceived competence and perceived value and the classroom-related emotions were collected in a different session. Data was gathered by a research assistant and by trained undergraduate students during regular classes (except Math classes).

Data Analysis

Descriptive statistics and correlation analyses were carried out using SPSS version 21 (IBM 2012). To test differences between the strength of the correlations, the procedure implemented in Statistica version 12 (StatSoft 2013) was used. A model of relationships between cognitive appraisals (perceived competence and value), emotions and academic achievement was analyzed through Structural Equation Modeling using Maximum likelihood estimation in Amos version 21.0 (Arbuckle 2012). Taking into consideration that chi-square values are highly sensitive to sample dimension, namely when samples are higher than 200 participants, several other indicators were used to evaluate the models goodness of fit: CFI, TLI 
How do you feel about math?

and RMSEA. Values higher than .90 for CFI and TLI are usually considered as indicating a good fit of the models to the data as well as values lower than .08 for RMSEA (Kline 2011). However Raykov and Marcoulides (2006) advocate a more conservative approach indicating a threshold of .95 for CFI and TLI and values lower than .05 for RMSEA, along with a narrow confidence interval $(\mathrm{CI})$.

\section{Results}

Descriptive statistics for classroom and test related emotions are presented in Table 1. Positive emotions are higher than negative both in classroom and test related emotions. In classroom related emotions pride shows the highest value whereas in test-related emotions relief is the emotion with the higher score. In both situations anger is the least felt of the emotions.

--- Table 1 about here ---

Correlation analyses between cognitive appraisals (perceived competence and value) and emotions (Table 1) show that perceived competence and value are negatively related to negative emotions and positively related to positive emotions(except for relief which relates negatively despite these relationships being very small). This pattern of relationships occurs both for classroom and test-related emotions. However, the magnitude of the correlations was stronger between cognitive appraisals and classroom emotions $\left(M_{|r|}=0.51\right)$ than between cognitive appraisals and test emotions $\left(M_{|r|}=0.36 ; 0.42\right.$ if relief is excluded), and the difference between them is statistically significant ( $p<0.001$ including all emotions; $p=0.012$ when relief is excluded).

In classroom situations positive activating (enjoyment and pride) and negative deactivating emotions (hopelessness and boredom) show the strongest correlations with cognitive appraisals, whereas in test situations positive activating emotions (enjoyment and pride) exhibit the strongest correlations to cognitive appraisals. Moreover the difference in 
How do you feel about math?

correlations is significantly higher for negative emotions $\left(\Delta_{M|r|}=0.12\right.$ taking into account the negative emotions that are common to both situations, $p<0.001)$ than for positive ones $\left(\Delta_{M|r|}=0.02, p=0.692\right)$. Additionally this difference is higher for the relationships between value and negative emotions $\left(\Delta_{M|r|}=0.18, p<0.001\right)$ than it is for the relations between negative emotions and perceived competence. In the relationships between cognitive appraisals and the positive activating emotions (enjoyment and pride) there are also differences which arise between value and perceived competence. Thus value shows significantly stronger correlations with positive activating emotions in class situations $\left(\Delta_{M|\mathrm{r}|}=0.07, p=0.008\right)$, whereas the relations between perceived competence and positive activating emotions are similar in the two settings $\left(\Delta_{M|r|}=0.03, p=0.146\right)$.

Correlation analyses between emotions and achievement show that positive emotions are positively related to grades and negative emotions are negatively related (Table 1). The differences observed in the magnitude of the relationships between class-related and test-related emotions with cognitive appraisals were also found in the case of grades $\left(M_{|r|}=0.39\right.$ for classroom emotions and $M_{|r|}=0.27$ for test emotions, or $M_{|r|}=0.32$ if relief is excluded; $p<0.001$ including all emotions and $p=0.048$ when relief is excluded). Moreover, and similar to what occurs in the relations between cognitive appraisals and emotions, here again the difference is mainly due to the association between negative emotions and math achievement. The association between positive activating emotions is similar in both situations $\left(\Delta_{M|r|}=0.01\right.$, $p=0.557$ ), whereas negative emotions correlations are significantly stronger for class than for test situations $\left(\Delta_{M \mid \mathrm{r}}=0.15, p<0.001\right)$

--- Figure 2 about here ---

--- Figure 3 about here ---

The associations between cognitive appraisals, emotions and performance in mathematics were tested in two separate models using SEM. In order to check for multicollinearity problems we calculated the means for each latent variable and included them 
How do you feel about math?

in a regression analysis as predictors of math achievement. As indicators of collinearity we used both the variance inflation factor (VIF) and tolerance measures provided by SPSS (IBM 2012), taking into consideration the thresholds of 3 for VIF and the corresponding value of 0.33 for tolerance (Hair et al. 2009; Kline 2011; Kock and Lynn 2012). Besides these indicators we also looked for correlations between the latent variables in the models in order to decide which ones to eliminate. Thus, enjoyment was eliminated from the models as well as anger in the classrelated emotions model and hopelessness, anger and anxiety has been tested in three different models (all including relief and pride) for test-related emotions.

Regarding cognitive appraisals, both models look at value and perceived competence and each latent variable is defined by 3 items. Goodness-of-fit indices are good, $\chi^{2}=26.9, d f=8$, $p=.001 ; \mathrm{CFI}=0.99 ; \mathrm{TLI}=0.99 ; \mathrm{RMSEA}=0.045$ (90\% CI: 0.027 to 0.065$)$, and the factor loadings are higher than 0.74. In terms of emotions, the models examined the simultaneous influence of the discrete math emotions reported in classroom or in test situations with the exception of enjoyment both for class and test related emotions and anger in class-related emotions. Each latent variable of emotions is defined by the corresponding four items in each. For class related emotions the model shows adequate goodness-of-fit indices, $\chi^{2}=415.5, d f=98, p<.001$; $\mathrm{CFI}=0.97$; TLI=0.96; RMSEA=0.052 (90\% CI: 0.047 to 0.057$)$ with the factor loadings ranging from 0.57 to 0.91 . For test related emotions all the three models show adequate fit to the data, $\chi^{2}=270.1, d f=511, p<.001 ; \mathrm{CFI}=0.97 ; \mathrm{TLI}=0.96 ; \mathrm{RMSEA}=0.059$ (90\% CI: 0.053 to 0.066 for the model including anxiety; $\chi^{2}=262, d f=51, p<.001 ;$ CFI $=0.97 ;$ TLI $=0.96 ;$ RMSEA $=0.058$ ( $90 \%$ CI: 0.052 to 0.065 ), for the model including hopelessness; $\chi^{2}=220.7, d f=51, p<.001$; $\mathrm{CFI}=0.98 ; \mathrm{TLI}=0.97 ; \mathrm{RMSEA}=0.052(90 \% \mathrm{CI}: 0.045$ to 0.059$)$ for the model including anger. The factor loadings for test related emotions ranging from 0.65 to 0.88 . The models took into consideration the inter-relations between the different emotions and the inter-relations between value and perceived competence by correlating the error terms of each latent variable. Given that gender can affect value and perceived competence, gender effects were controlled. Also the effects of previous achievement on actual Math achievement was controlled as well as the effects of this variable on value and perceived competence. The models tested took into account 
How do you feel about math?

all the possible relationships between cognitive appraisals, emotions and math achievement except for the effects of value on math achievement, as these effects were not significant. Instead we correlated the error terms of both variables in the class model, because this relationship was significant.

The results obtained show that all models of the relationships between the latent variables (Figures 2 and 3), fit the data well: $\chi^{2}=896.9, d f=301, p<.001 ; \mathrm{CFI}=0.97$; TLI=0.97; RMSEA $=0.040$ (90\% CI: 0.037 to 0.043 ) for the classroom situation; for the test situation: $\chi^{2}=770.8, d f=213, p<.001 ; \mathrm{CFI}=0.97 ; \mathrm{TLI}=0.96 ; \mathrm{RMSEA}=0.046$ (90\% CI: 0.043 to 0.050$)$, for the model with hopelessness, $\chi^{2}=758.0, d f=213, p<.001 ; \mathrm{CFI}=0.97$; TLI=0.96; RMSEA $=0.046$ (90\% CI: 0.042 to 0.049 ) for the model with anger and $\chi^{2}=784.1, d f=213, p<.001 ; \mathrm{CFI}=0.97$; TLI=0.96; RMSEA=0.047 (90\% CI: 0.043 to 0.050 ) for the model with anxiety.

The pattern of relationships between cognitive appraisals and emotions is similar to the one observed in correlations except for the positive relationship between value and anxiety and the negative relationship between perceived competence and relief, both in the test situation. Perceived competence is the strongest predictor of achievement emotions both in classroom and test situations $\left(M_{|b|}{ }^{1}=0.44\right.$ in test situations and $M_{|b|}=0.41$ in classroom situations $v$ s. $M_{|b|}=0.15$ for value in test situations and $M_{|b|}=0.34$ in classroom situations). However, the pattern of the magnitude of the relationships between the cognitive appraisals and emotions is slightly different for value and perceived competence. Perceived competence shows slightly higher values for the relationships with emotions in test situation whereas value presents stronger correlations with class-related emotions. The percentage of variance of achievement emotions explained by cognitive appraisals is higher in the case of class-related emotions $\left(M_{R}^{2}=0.47\right)$ than in the case of test-related emotions $\left(M_{R}^{2}=0.31\right.$ excluding relief $)$.

From the point of view of emotions, the stronger relationships are from perceived competence to pride and hopelessness, both in the test situation. In the class situation the relationship between boredom and value is the strongest despite the fact that the relationships of pride, anxiety, and hopelessness with perceived competence as well as the relationship between

\footnotetext{
${ }^{1}$ Mean regression coefficient (absolute value)
} 
How do you feel about math?

pride and value show similar values. In the case of relationships between emotions and academic achievement, only hopelessness (in both test and class situations) and anger (in test situation) were significant predictors of student Math achievement, both negatively.

\section{Discussion}

The purpose of this study has been to analyze the interrelationships between cognitive appraisals, emotions and Math achievement in early adolescents. Findings showed that cognitive appraisals relate positively with pleasant emotions and negatively with unpleasant emotions. The same pattern was found for the relationships between emotions and Math achievement. A second aim of this study was to test whether there were differences in the relationships between cognitive appraisals, emotions and achievement according to the situation (test or class). The results support the existence of differences between the two situations for the relationships between cognitive appraisals and emotions but not for the relationships between emotions and math achievement. The relationships between cognitive appraisals and emotions were stronger in class situations, and the differences were mainly due to the association between negative emotions and cognitive appraisals.

Cognitive appraisals and emotions

In line with the main assumptions of CVT (Pekrun, 2006, 2013), we found a strong positive relationship between student cognitive appraisals (perceived value and competence) and their experience of pleasant emotions (except relief), both in classroom and test situations. Conversely, perceived value and perceived competence were negatively related to all negative emotions, both activating and deactivating in the two settings, therefore confirming our first hypothesis.

Also as hypothesized we found that the relationship between student cognitive appraisals and their positive activating (enjoyment and pride) or negative deactivating (boredom and hopelessness) emotions was stronger than the relationship between student cognitive 
How do you feel about math?

appraisals and their positive deactivating (relief) or negative activating emotions (anger and anxiety). Indeed, according to CVT (Pekrun 2006, 2009), while positive activating emotions are consensually considered beneficial and negative deactivating emotions detrimental, the role played by positive deactivating and negative activating achievement emotions is more complex and ambiguous. In some cases they may produce positive effects, but in other cases negative (Pekrun et al. 2002; Pekrun et al. 2009), which may explain the null or very weak correlation obtained between cognitive appraisals and relief.

The results of SEM analysis revealed that perceived competence was the strongest predictor of most achievement emotions, namely pride, hopelessness and anxiety both for class and test situations. This finding highlights the importance of feelings of competence for emotional experience in Math learning (Frenzel et al. 2007; Goetz et al. 2008; Luo et al. 2014; Pekrun et al. 2011).

Emotions and academic achievement

The second hypothesis tested in this study assumed that student achievement emotions would affect Math achievement. Since students experience a wide range of emotions, which do not occur separately, several emotions were considered simultaneously in our models to ascertain the relative weight of each in explaining student math outcomes.

Despite correlation analyses showing that all emotions were significantly related to Math achievement, when they were simultaneously included in the models, only feelings of anger in test situations and of hopelessness in both tests and classes were related to student Math achievement. These effects are most likely due to the interrelationships between emotions and are consistent with previous findings from Burić and Sorić (2012) which suggest that including competing emotions in the same model weakens their effects on achievement measures. Moreover, controlling for previous Math achievement and including Math perceived competence in the models makes the emergence of significant relationships between emotions and Math achievement more difficult (Ahmed et al. 2013; Ma \& Xu, 2004; Pinxten et al. 2014). 
How do you feel about math?

Among the different emotions considered in the current research hopelessness has emerged as the most prominent in its relationship to math achievement. Hopelessness is a negative deactivating outcome emotion which is detrimental to learning and achievement (Burić and Sorić 2012; Pekrun et al. 2009). Being a prospective outcome emotion (Pekrun 2006), feeling hopeless towards Math can lead to a failure cycle culminating in learned hopelessness (Au et al. 2010). Indeed, if students believe there is nothing they can do to change their situation and they give up trying their effort and involvement in achievement tasks will decrease and that will harm their math performance. In turn, the poorer the results obtained the more likely the "confirmation" of previous negative competence perceptions will be which will further undermine student motivation, reinforcing prior hopeless feelings. So one of the major risks is that these relationships which, as suggested in CVT, are likely to be affected by reciprocal causation (Pekrun 2006), give rise to a negative feedback loop between student hopelessness and their poor math achievements over time.

Relationships between cognitive appraisals and emotions in class and test situations

In line with our third hypothesis we found stronger associations between cognitive appraisals and emotions for class related emotions. These findings are consistent with previous research by Goetz et al. (2012) who reported weaker correlations between self-concept and homework emotions than between self-concept and classroom emotions. However, in our results, the difference between the class and test situations is mainly due to the differences in the associations between negative emotions and cognitive appraisals. In other words, the value that students ascribe to mathematics and their perceived competence in math are more strongly related to the negative emotions they experienced in classroom situations than to the negative emotions experienced in test situations.

According to Pekrun et al. (2011) these settings have different functions and different social structures which seem to influence the role of emotions in the interplay between motivation and achievement. As such, the differences between classroom and test situations may be due to the fact that classes are constant routines in a student's life, while test situations 
How do you feel about math?

are more infrequent. In classroom settings students can see their progress or lack of it and their skills or difficulties as well as their accomplishments or failures, on a daily basis. This continuous input of information that students collect from their interactions with the task, with teachers and colleagues in the classroom, is central to their motivational characteristics (Ahmed et al. 2013; Furrer et al. 2014) and could support the strong relationship between cognitive appraisals and emotions in the classroom. Moreover, in classroom situations there are a lot more inputs from social factors and higher emotional investment compared to test situations

(Raccanello et al. 2013) which may trigger changes in the learning process. This on-going way in which students and teachers interact is more noticeable in the classroom and has the potential to help students to adapt and regulate their emotions according to the reasons why they do the tasks and by helping them to interpret their outcomes in math.

The results of SEM analysis additionally highlighted the importance of perceived competence to the feelings of pride and hopelessness in test situations. Students who feel more competent feel less hopeless during tests and prouder of the scores they achieve. The pride or hopeless experienced in test settings can be explained by student appraisals of previous similar situations. Success in math tests that students perceive to be caused by internal factors will reinforce a sense of control over the outcomes obtained (Pekrun 2006; Pekrun et al. 2011), while failure can reinforce the lack of feelings of control. These emotions are probably more evident in test situations where students are able to control the appraisal of their past outcomes in this setting, where assessment is usually based on an objective measure (grades) and results can easily be interpreted through self-reference, leading to feelings of control (or lack of control in the case of hopelessness) over achievement outcomes.

Perceived value showed slightly different patterns in the classroom and test situations, relating more strongly to emotions in the classroom than in test situations, with the exception of the relation with anxiety which is not significant in the class situation. Here a particular note on the relationship between value and anxiety which is positive and in contradiction to that of correlation analysis. This positive association in combination with its strength highlights the possibility that the effect of value on anxiety is connected to perceived competence. Students 
How do you feel about math?

who feel confident in their abilities and value the task probably feel less anxious than students that equally value the task but lack confidence in their capabilities. CVT supports this idea claiming that negative activating emotions, such as anxiety can have ambivalent effects on student outcomes (Pekrun 2006, 2009) and can be managed in different ways taking into account the level of confidence and perceived competence of the student.

\section{Limitations}

Some limitations of this study should be mentioned. First the cross-sectional and correlational nature of the study involving concurrent data on motivation indicators and emotions does not allow for any conclusion on causal relations. Despite the fact that the model tested posits that cognitive appraisals indicators predict emotions, which predict Math achievement, other paths can be assumed looking at the relationships between emotions and cognitive appraisals as dynamic processes sustained by reciprocal causation over time (Pekrun et al. 2007). A second limitation is that emotions were assessed as trait-like emotions precluding any generalisation for state-like emotions. The model proposed can be conceptually sound for trait-like emotions but it makes less sense when we talk about state-like emotions.

Implications

Despite these limitations our findings suggest that hopelessness plays an important role in the interchanges between cognitive appraisals and Math achievement. This draws attention to Math teachers and the learning environments that they set up, as feeling hopeless can lead to a cycle of failure (Au et al. 2010) which is something that should be avoided at all costs in learning contexts. Teachers should be aware of the value placed by students on the task itself and on the outcomes, as well as of their feelings of competence. It is important to understand whether the value attributed to mathematical tasks means that students want to learn for pleasure and for curiosity or rely on external incentives. In the first case students will be able to overcome boredom and/or anxiety, seeking help when they face difficulties and therefore feeling less hopeless. As such, it will be important for teachers to think about the strategies used 
How do you feel about math?

and if they are the more effective in promoting student intrinsic value to the tasks (Tapia and Montero, 2004).

Furthermore it is important to think about the kind of assessment that the teacher proposes in order to minimize the detrimental effects that it can have. The positive association between value and anxiety in the test situation calls attention to the importance of tests, which are probably the main (if not the only) determinant of student grades. This characteristic of tests places students under strong pressure, namely those who value Math and/or Math grades and particularly those with low perceived competence. Thus if evaluation could have a more formative essence instead of summative, assuming its role of learning regulation, which could improve student confidence in their math skills and in this way reduce the levels of anxiety usually related to tests (Black and Wiliam, 1998; Ugodulunwa and Okolo, 2015).

Student beliefs about their competence and control regarding the tasks and activities can facilitate or hinder achievement. As such, teachers should think about the teaching strategies they use and the learning environment they promote in order to contribute to the development of students' positive beliefs and to the self-regulatory processes related to those beliefs. When teachers give emotional support, value personal development and show positive expectations of students, they promote positive emotional feelings, higher levels of perceived control and involvement (Ahmed et al. 2013; Furrer et al. 2014). Via different means, including verbal and nonverbal messages, environments shape student interests, competence beliefs and values which in turn underpin their achievement emotions (Pekrun et al. 2007). In this context classrooms are important settings for these "shaping" processes during the learning process.

\section{References}

Ahmed, W. Minnaert, A., Van Der Werf, G., \& Kuyper, H. (2010). Perceived Social Support and Early Adolescents' Achievement: The Mediational Roles of Motivational Beliefs and Emotions. Journal of Youth and Adolescence. doi: 10.1007/s10964-008-9367-7 
How do you feel about math?

Ahmed, W., Van Der Werf, G., Kuyper, H., \& Minnaert, A. (2013). Emotions, Self-Regulated Learning, and Achievement in Mathematics: A Growth Curve Analysis. Journal of Educational Psychology. doi: 10.1037/a0030160

Arbuckle, J. (2012). Amos (Version 21.0) [Computer Program]. Chicago: SPSS.

Artino, A. R., La Rochelle, J. S., \& Durning, S. J. (2010). Second-year medical students' motivational beliefs, emotions, and achievement. Medical Education. doi:10.1111/j.13652923.2010.03712.x

Au, R., Watkins, D. A., \& Hattie, J. (2010) Academic risk factors and deficits of learned hopelessness: A longitudinal study of Hong Kong secondary school students. Educational Psychology. doi: 10.1080/01443410903476400

Black, P., \& Wiliam, D. (1998). Assessment and classroom learning. Assessment in education: Principles, Policy \& Practice. doi: 10.1080/0969595980050102

Burić, I., \& Sorić, I. (2012). The role of test hope and hopelessness in self-regulated learning: Relations between volitional strategies, cognitive appraisals and academic achievement. Learning and Individual Differences. doi: 10.1016/j.lindif.2012.03.011

Daniels, L. M., Stupnisky, R. H., Pekrun, R., Haynes, T. L., Perry, R. P., \& Newall, N. E. (2009). A longitudinal analysis of achievement goals: From affective antecedents to emotional effects and achievement outcomes.Journal of Educational Psychology. doi: $10.1037 / \mathrm{a} 0016096$

Dettmers, S., Trautwein, U., Lüdtke, O., Goetz, T., Frenzel, A. C., \& Pekrun, R. (2011). Students' emotions during homework in mathematics: Testing a theoretical model of antecedents and achievement outcomes. Contemporary Educational Psychology. doi: 10.1016/j.cedpsych.2010.10.001

Dündar, S., Güvendir, M. A., Kocabiyik, O. O., \& Papatga, E. (2014). Which elementary school subjects are the most likeable, most important, and the easiest? Why?: A study of science and technology, mathematics, social studies, and Turkish. Educational Research and Reviews. doi:10.5897/ERR2014.1755 
How do you feel about math?

Else-Quest, N. M., Hyde, J. S., \& Linn, M. C. (2010). Cross-national patterns of gender differences in mathematics: a meta-analysis. Psychological Bulletin. doi: $10.1037 / \mathrm{a} 0018053$

Erturan, S., \& Jansen, B. (2015). An investigation of boys' and girls' emotional experience of math, their math performance, and the relation between these variables. European Journal of Psychology of Education. doi: 10.1007/s10212-015-0248-7

Feldman, D. B., \& Kubota, M. (2015). Hope, self-efficacy, optimism, and academic achievement: Distinguishing constructs and levels of specificity in predicting college grade-point average. Learning and Individual Differences. doi:10.1016/j.lindif.2014.11.022

Frenzel, A. C., Pekrun, R., \& Goetz, T. (2007). Girls and mathematics - A "hopeless" issue? A control-value approach to gender differences in emotions towards mathematics. European Journal of Psychology of Education. doi:10.1007/BF03173468

Furrer, C. J., Skinner, E. A., \& Pitzer, J. R. (2014). The influence of teacher and peer relationships on students' classroom engagement and everyday resilience. In D. J. Shernoff \& J. Bempechat (Eds.), National Society for the Study of Education Yearbook. Engaging Youth in Schools: Empirically-Based Models to Guide Future Innovations, vol. 113, (pp. 101-123). Columbia University: Teachers's College.

Goetz, T., Bieg, M., Lüdtke, O., Pekrun, R., \& Hall, N. C. (2013). Do girls really experience more anxiety in mathematics?. Psychological Science. doi: 10.1177/0956797613486989

Goetz, T., Cronjaeger, H., Frenzel, A. C., Lüdtke, O., \& Hall, N. C. (2010). Academic selfconcept and emotion relations: Domain specificity and age effects. Contemporary Educational Psychology, doi:10.1016/j.cedpsych.2009.10.001

Goetz, T., Frenzel, A. C., Hall, N. C., \& Pekrun, R. (2008). Antecedents of academic emotions: Testing the internal/external frame of reference model for academic enjoyment. Contemporary Educational Psychology. doi:10.1016/j.cedpsych.2006.12.002 
How do you feel about math?

Goetz, T., Frenzel, A. C., Pekrun, R., \& Hall, N. C. (2006). The domain specificity of academic emotional experiences. The Journal of Experimental Education, doi:

10.3200/JEXE.75.1.5-29

Goetz, T., Frenzel, A. C., Pekrun, R., Hall, N. C., \&Lüdtke, O. (2007). Between- and withindomain relations of students' academic emotions. Journal of Educational Psychology. doi: 10.1037/0022-0663.99.4.715

Goetz, T., Nett, U. E., Martiny, S. E., Hall, N. C., Pekrun, R., Dettmers, S., \& Trautwein, U. (2012). Students' emotions during homework: Structures, self-concept antecedents, and achievement outcomes. Learning and Individual Differences. doi:10.1016/j.lindif.2011.04.006

Hair, J.F., Black, W.C., Babin, B.J., \& Anderson, R.E. (2009). Multivariate data analysis. New Jersey, USA: Prentice Hall

Huang, C. (2011). Achievement goals and achievement emotions: A meta-analysis. Educational Psychology Review. doi: 10.1007/s10648-011-9155-x

IBM Corp. (2012). IBM SPSS statistics for Windows, Version 21.0. Armonk, NY: IBM Corp.

Keeley, J., Zayac, R., \& Correia, C. (2008). Curvilinear relationships between statistics anxiety and performance among undergraduate students: Evidence for optimal anxiety. Statistics Education Research Journal, 7(1), 4-15.

Kline, R. (2011). Principles and practice of structural equation modeling (3rd ed.). New York: Guilford Press.

Kock, N., \& Lynn, G. S. (2012). Lateral collinearity and misleading results in variance-based SEM: An illustration and recommendations. Journal of the Association for Information Systems, 13(7), 546-580. Available at SSRN: http://ssrn.com/abstract=2152644.

Kyttälä, M., \& Björn, P. M. (2010). Prior mathematics achievement, cognitive appraisals and anxiety as predictors of Finnish students' later mathematics performance and career orientation. Educational Psychology. doi: 10.1080/01443411003724491 
How do you feel about math?

Lam, U. F., Chen, W. W., Zhang, J., \& Liang, T. (2015). It feels good to learn where I belong: School belonging, academic emotions, and academic achievement in adolescents. School Psychology International. doi:10.1177/0143034315589649

Levi, U., Einav, M., Ziv, O., Raskind, I., \& Margalit, M. (2014). Academic expectations and actual achievements: The roles of hope and effort. European Journal of Psychology of Education. doi:10.1007/s10212-013-0203-4

Lichtenfeld, S., Pekrun R., Stupnisky, R., Reiss, K., \& Murayama, K. (2012). Measuring students' emotions in the early years: The Achievement Emotions QuestionnaireElementary School (AEQ-ES). Learning and Individual Differences. doi:10.1016/j.lindif.2011.04.009

Lipnevich, A. A., MacCann, C., Bertling, J. P., Naemi, B., \& Roberts, R. D. (2012). Emotional reactions toward school situations relationships with academic outcomes. Journal of Psychoeducational Assessment. doi: 10.1177/0734282912449445

Lindberg, S. M., Hyde, J. S., Petersen, J. L., \& Linn, M. C. (2010). New trends in gender and mathematics performance: a meta-analysis.Psychological Bulletin, doi: 10.1037/a0021276Luo, W., Lee, K., Ng, P. T., \& Ong, J. W. (2014). Incremental beliefs of ability, achievement emotions and learning of Singapore students. Educational Psychology. doi: 10.1080/01443410.2014.909008

Ma, X., \& Xu, J. (2004). The causal ordering of mathematics anxiety and mathematics achievement: A longitudinal panel analysis. Journal of Adolescence. doi:10.1016/j.adolescence.2003.11.003

Macher, D., Paechter, M., Papousek, I., Ruggeri, K., Freudenthaler, H. H., \& Arendasy, M. (2013). Statistics anxiety, state anxiety during an examination, and academic achievement. British Journal of Educational Psychology. doi:10.1111/j.20448279.2012.02081.x

Malkovsky, E., Merrifield, C., Goldberg, Y., \& Danckert, J. (2012). Exploring the relationship between boredom and sustained attention. Experimental Brain Research, doi : $10.1007 / \mathrm{s} 00221-012-3147-\mathrm{z}$ 
How do you feel about math?

Meece, J. L., Wigfield, A., \& Eccles, J. S. (1990). Predictors of math anxiety and its influence on young adolescents' course enrollment intentions and performance in mathematics. Journal of Educational Psychology. doi: 10.1037/0022-0663.82.1.60

Mega, C., Ronconi, L., \& De Beni, R. (2014). What makes a good student? How emotions, selfregulated learning, and motivation contribute to academic achievement. Journal of Educational Psychology. doi: 10.1037/a0033546

Meyer, D., \& Turner, J. (2006).Re-conceptualizing emotion and motivation to learn in classroom contexts. Educational Psychology Review. doi: 10.1007/s10648-006-9032-1

Monteiro, V., Mata, L., M., \& Peixoto, F. (2015). Intrinsic Motivation Inventory: Psychometric properties in the context of first language and mathematics learning. Psicologia: Reflexão e Crítica. doi:10.1590/1678-7153.201528302

OECD, (2014). PISA 2012 results: What students know and can do - Student performance in mathematics, reading and science (Vol. 1 Revised edition). doi:

$10.1787 / 9789264201118$-en

Peixoto, F., Mata, L., Monteiro, V., Sanches, C., \& Pekrun, R. (2015). The Achievement Emotions Questionnaire: Validation for pre-adolescent students. European Journal of Developmental Psychology. doi:10.1080/17405629.2015.1040757

Pekrun, R. (2006). The control-value theory of achievement emotions: Assumptions, corollaries, and implications for educational research and practice. Educational Psychology Review. doi: 10.1007/s10648-006-9029-9

Pekrun, R. (2009). Global and local perspectives on human affect: Implications of the controlvalue theory of achievement emotions. In M. Wosnitza, S. A. Karabenick, A. Efklides, \& P. Nenniger (Eds.), Contemporary motivation research: From global to local perspectives (pp. 97- 115). Toronto, Ontario, Canada: Hogrefe.

Pekrun, R. (2013). Emotions, motivation, and self-regulation: Common principles and future directions. In N. Hall \& T. Goetz (Eds). Emotion, motivation, and self-regulation: A handbook for teachers. Bingley: Emerald Group Publishing Limited. 
How do you feel about math?

Pekrun, R., Elliot, A. J., \& Maier, M. A. (2006). Achievement goals and discrete achievement emotions: A theoretical model and prospective test.Journal of Educational Psychology, doi: 10.1037/0022-0663.98.3.583

Pekrun, R., Elliot, A. J., \& Maier, M. A. (2009). Achievement goals and achievement emotions: Testing a model of their joint relations with academic performance. Journal of Educational Psychology. doi:10.1037/a0013383

Pekrun, R., Frenzel, A. C., Goetz, T., \& Perry, R. P. (2007). The control-value theory of achievement emotions: An integrative approach to emotions in education. In P. A. Schutz \& R. Pekrun (Eds.), Emotion in education (pp. 13-36). San Diego, CA, US: Elsevier Academic Press.

Pekrun, R., Goetz, T., Daniels, L. M., Stupnisky, R. H., \& Perry, R. P. (2010). Boredom in achievement settings: Exploring control-value antecedents and performance outcomes of a neglected emotion. Journal of Educational Psychology, doi : 10.1037/a0019243

Pekrun, R., Goetz, T., Frenzel, A. C., Barchfeld, P., \& Perry, R. P. (2011). Measuring emotions in students' learning and performance: The Achievement Emotions Questionnaire (AEQ). Contemporary Educational Psychology. doi:10.1016/j.cedpsych.2010.10.002

Pekrun, R., Goetz, T., Perry, R. P., Kramer, K., Hochstadt, M., \& Molfenter, S. (2004). Beyond test anxiety: Development and validation of the Test Emotions Questionnaire (TEQ). Anxiety, Stress \& Coping, doi: 10.1080/10615800412331303847

Pekrun, R., Goetz, T., Titz, W., \& Perry, R.P. (2002). Academic emotions in students' selfregulated learning and achievement: A program of quantitative and qualitative research. Educational Psychologist. doi: 10.1207/S15326985EP3702_4

Pekrun, R., Hall, N., Goetz, T., \& Perry, R. P. (2014). Boredom and academic achievement: Testing a model of reciprocal causation. Journal of Educational Psychology. doi: $10.1037 / \mathrm{a} 0036006$

Pinxten, M., Marsh, H. W., De Fraine, B., Van Den Noortgate, W., \& Van Damme, J. (2014). Enjoying mathematics or feeling competent in mathematics? Reciprocal effects on 
How do you feel about math?

mathematicsachievement and perceived math effort expenditure. British Journal of Educational Psychology. doi: 10.1111/bjep.12028

Raccanello, D., Brondino, M., \& Bernardi, B. (2013) Achievement emotions in elementary, middle, and high school: How do students feel about specific contexts in terms of settings and subject-domains? Scandinavian Journal of Psychology. doi: 10.1111/sjop.12079

Radišić, J., Videnović, M., \& Baucal, A. (2015). Math anxiety - Contributing school and individual level factors. European Journal of Psychology of Education. doi:10.1007/s10212-014-0224-7

Raykov, T., \& Marcoulides, G. A. (2006). A first course in structural equation modeling (2nd ed.). Mahwah, NJ: Lawrence Erlbaum Associates.

Richardson, M., Abraham, C., \& Bond, R. (2012). Psychological correlates of university students' academic performance: a systematic review and meta-analysis. Psychological Bulletin, doi: 10.1037/a0026838

Sorić, I., Penezić, Z., \& Burić, I. (2013). Big Five personality traits, cognitive appraisals and emotion regulation strategies as predictors of achievement emotions. Psihologijske Teme, 22(2), 325-349.

StatSoft, Inc. (2013). Electronic statistics textbook. Tulsa, OK: StatSoft. Retrieved from: http://www.statsoft.com/textbook/.

Tapia, J. A., \& Montero, I. (2004). Orientação motivacional e estratégias motivadoras na aprendizagem escolar. In C. Coll, A. Marchesi, \& J. Palácios (Eds.), Desenvolvimento psicológico e educação 2. Psicologia da educação escolar (pp. 177-192). Porto Alegre: Artmed.

Trautwein, U., Lüdtke, O., Kastens, C., \& Köller, O. (2006). Effort on homework in grades 5 through 9: Development, motivational antecedents, and the association with effort on classwork. Child Development, doi:10.1111/j.1467-8624.2006.00921.x.Ugodulunwa, C., \& Okolo, U. P. (2015). Effects of formative assessment on mathematics test anxiety and performance of senior secondary school students in Jos, Nigeria. Journal of Research \& Method in Education. doi: 10.9790/7388-05223847 
How do you feel about math?

Villavicencio, F. T., \& Bernardo, A. B. (2013). Positive academic emotions moderate the relationship between self-regulation and academic achievement. British Journal of Educational Psychology. doi:10.1111/j.2044-8279.2012.02064.x

Weiner, B. (2007). Examining emotional diversity in the classroom: An attribution theorist considers the moral emotions. In P. A. Schutz \& R. Pekrun (Eds.), Emotion in education (pp. 75-88). Amsterdam: Academic Press.

Winberg, T. M., Hellgren, J. M., \& Palm, T. (2014). Stimulating positive emotional experiences in mathematics learning: Influence of situational and personal factors. European Journal of Psychology of Education. doi: 10.1007/s10212-014-0220-y

Wu, S. S., Willcutt, E. G., Escovar, E., \& Menon, V. (2014). Mathematics achievement and anxiety and their relation to internalizing and externalizing behaviors. Journal of Learning Disabilities. doi:10.1177/0022219412473154 
How do you feel about math?

Table 1 - Descriptive statistics and Correlations for all study variables

\begin{tabular}{|c|c|c|c|c|c|c|c|c|c|c|c|c|c|}
\hline & 1 & 2 & 3 & 4 & 5 & 6 & 7 & 8 & 9 & 10 & 11 & $M$ & $S D$ \\
\hline 1. Hopelessness & $.56^{* *}$ & $.70^{*}$ & $.72 * *$ & $.29 * *$ & $-.51 * *$ & $-.53 * *$ & -.02 & $-.44 * *$ & $-.57 * *$ & $-.59 * *$ & $-.52 * *$ & 2.18 & 1.03 \\
\hline 3. Anxiety & $.49 * *$ & $.55^{* *}$ & $.61 * *$ & $.45^{* *}$ & $-.33 * *$ & $-.32 * *$ & $.10 * *$ & $-.28 * *$ & $-.16 * *$ & $-.38 * *$ & $-.32 * *$ & 2.50 & .94 \\
\hline 4. Boredom / Relief ${ }^{\mathrm{a}}$ & $.70 * *$ & $.67 * *$ & $.36 * *$ & ---- & 0.00 & $.09 * *$ & -.05 & $-.29 * *$ & $-.58 * *$ & $-.47 * *$ & $-.36 * *$ & 2.65 & 1.14 \\
\hline 5. Enjoyment & $-.61 * *$ & $-.50 * *$ & $-.22 * *$ & $-.77 * *$ & $.69 * *$ & $.80 * *$ & .01 & $.31 * *$ & $.64 * *$ & $.60 * *$ & $.36^{* *}$ & 3.26 & .94 \\
\hline 6. Pride & $-.63 * *$ & $-.48 * *$ & $-.24 * *$ & $.77 * *$ & $.65 * *$ & $.63 * *$ & .02 & $.38 * *$ & $.62 * *$ & $.64 * *$ & $.42 * *$ & 3.63 & .90 \\
\hline 7. Gender & $.11^{* *}$ & .01 & $.16^{* *}$ & $.11 * *$ & $-.08 * *$ & $-.11 * *$ & 1 & & & & & & \\
\hline 8. Previous Math Achievement & $-.36 * *$ & $-.26 * *$ & $-.20 * *$ & -.01 & $.38 * *$ & $.38 * *$ & -.03 & 1 & & & & & \\
\hline 10. Perceived Competence & $-.50 * *$ & $-.35 * *$ & $-.32 * *$ & -.03 & $.65^{* *}$ & $.66^{* *}$ & $-.16 * *$ & $.53 * *$ & $.50 * *$ & 1 & & & \\
\hline 11. Math achievement & $-.43 * *$ & $-.31 * *$ & $-.27 * *$ & $-.06 *$ & $.43 * *$ & $.43 * *$ & .02 & $.74 * *$ & $.34 * *$ & $.61 * *$ & 1 & & \\
\hline$M$ & 2.42 & 2.06 & 2.65 & 3.48 & 3.24 & 3.25 & ---- & 3.06 & 4.60 & 3.44 & 2.89 & & \\
\hline$S D$ & .98 & .92 & 1.04 & .93 & .94 & .94 & ---- & .89 & 1.24 & 1.33 & .87 & & \\
\hline
\end{tabular}

Descriptive statistics and correlations between study variables are presented below the diagonal for class-related emotions and above the diagonal for test-related emotions; $* \mathrm{p}<.05, * * \mathrm{p}<.01 ;{ }^{\mathrm{a}}$ Boredom was measured only in class situations relief was measured only in test. 


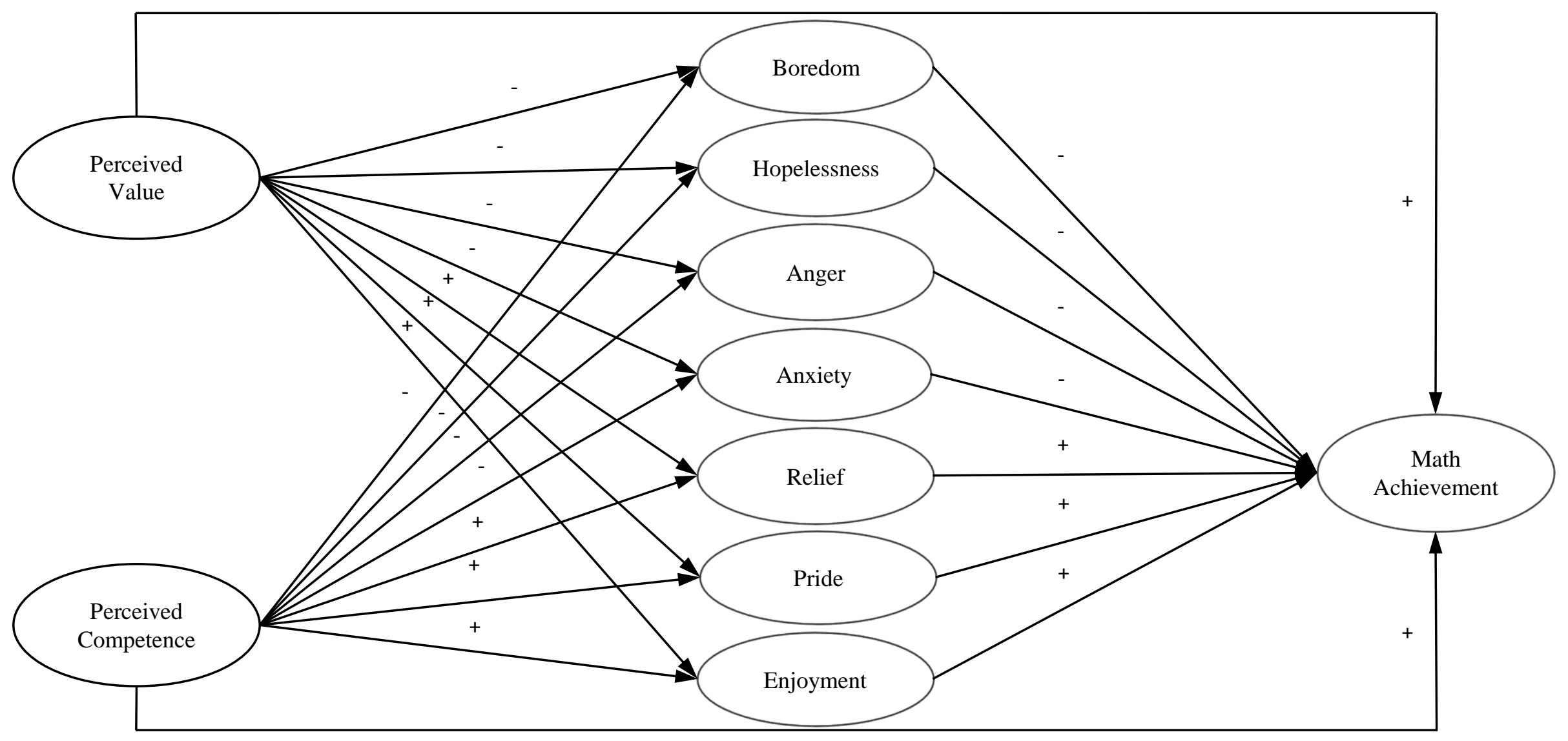

Figure 1.

Hypothesized relationships amongst study variables. Separate models were tested for class and test related emotions. 


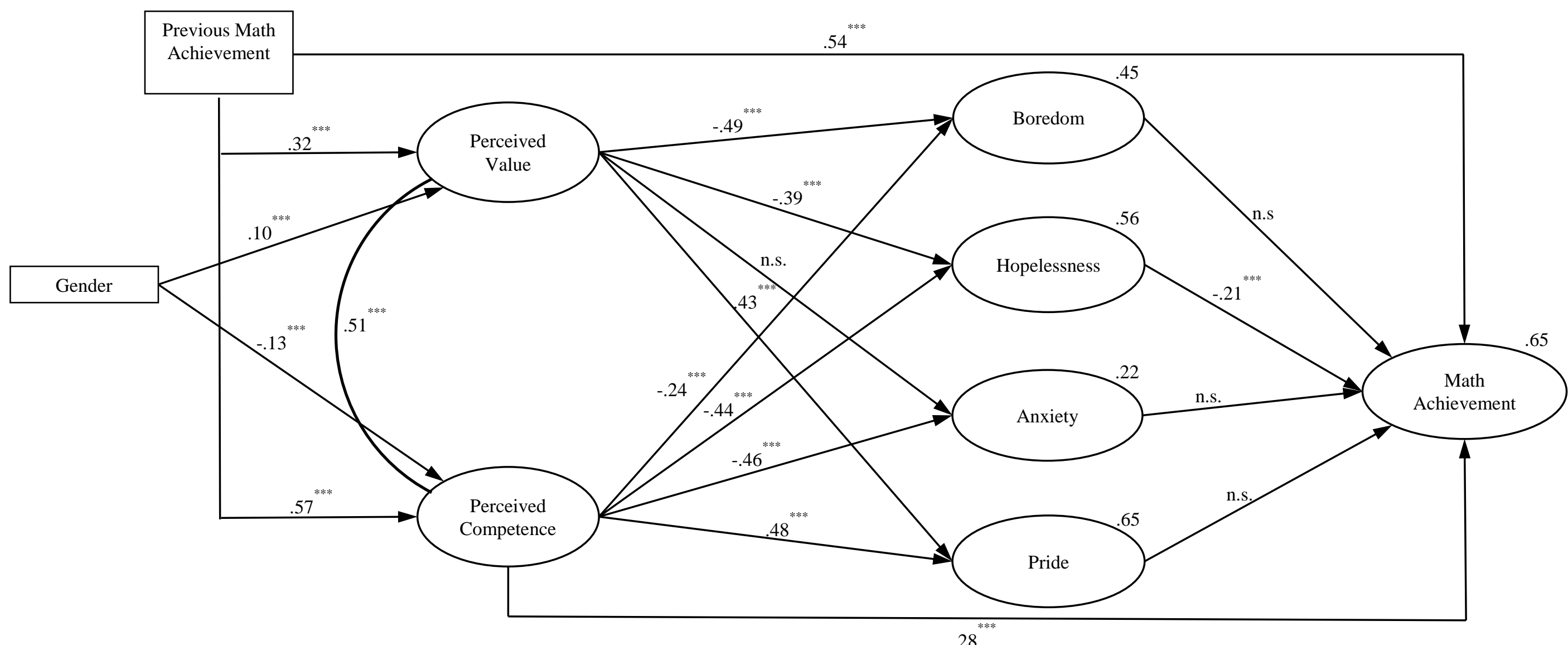

Figure 2.

Parameter estimates (standardised regression coefficients) for the structural equation models of the relationships between cognitive appraisals, achievement emotions and math achievement in class related emotions. Only latent variables are presented. n.s. $=$ non-significant, $* \mathrm{p}<.05, * * \mathrm{p}<.01, * * * \mathrm{p}<.001$ 


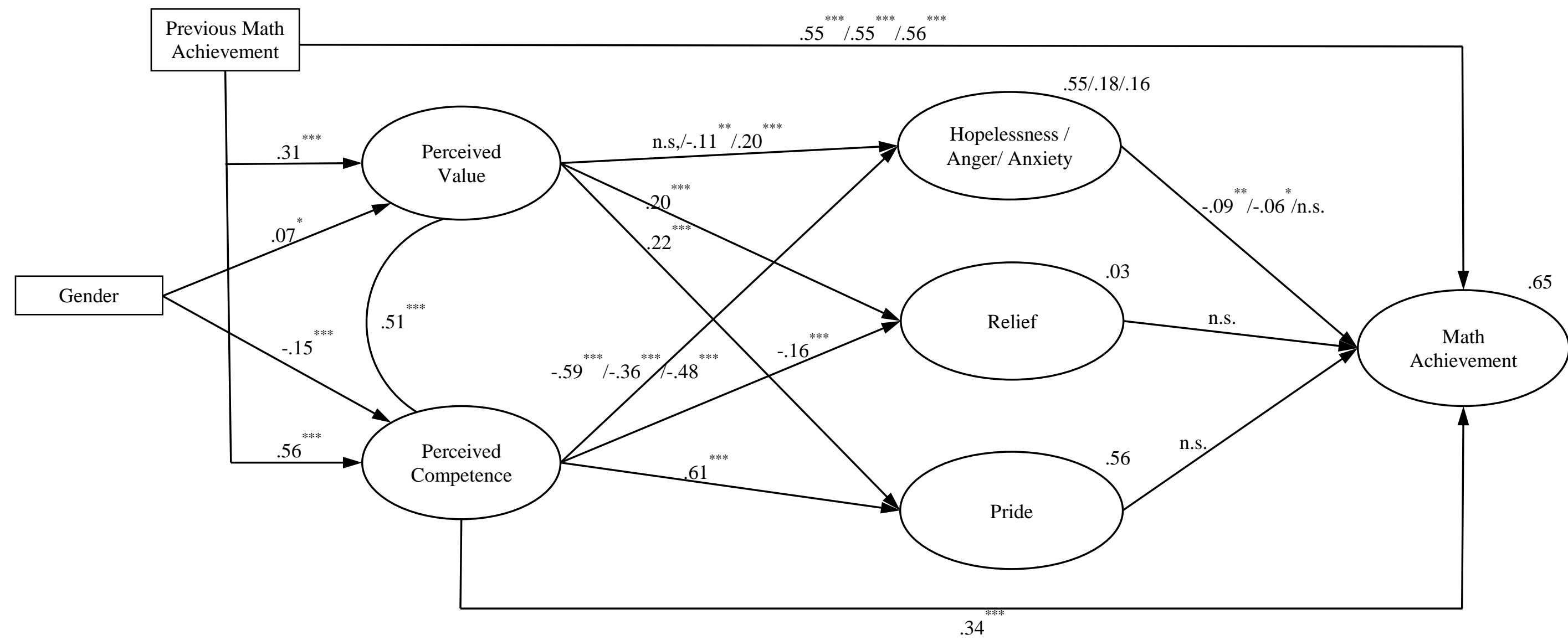

Figure 3.

Parameter estimates (standardised regression coefficients) for the structural equation models of the relationships between cognitive appraisals, achievement emotions and math achievement in test related emotions. Only latent variables are presented.The figure represents the three models tested for test-related emotions. When the parameter estimates are the same across the three models only one value is presented; when they differ, the first one to be presented is from the model with hopelessness, the second with anger and the third from the model with anxiety. n.s.= non-significant, $* \mathrm{p}<.05, * * \mathrm{p}<.01, * * * \mathrm{p}<.001$. 